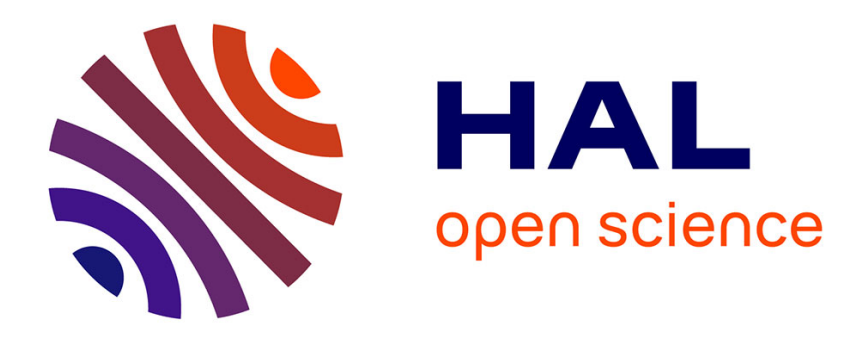

\title{
Critical Initiation Conditions for Gaseous Diverging Spherical Detonations
}

\author{
D. Desbordes
}

\section{To cite this version:}

D. Desbordes. Critical Initiation Conditions for Gaseous Diverging Spherical Detonations. Journal de Physique IV Proceedings, 1995, 05 (C4), pp.C4-155-C4-162. 10.1051/jp4:1995413 . jpa-00253712

\section{HAL Id: jpa-00253712 https://hal.science/jpa-00253712}

Submitted on 1 Jan 1995

HAL is a multi-disciplinary open access archive for the deposit and dissemination of scientific research documents, whether they are published or not. The documents may come from teaching and research institutions in France or abroad, or from public or private research centers.
L'archive ouverte pluridisciplinaire HAL, est destinée au dépôt et à la diffusion de documents scientifiques de niveau recherche, publiés ou non, émanant des établissements d'enseignement et de recherche français ou étrangers, des laboratoires publics ou privés. 


\title{
Critical Initiation Conditions for Gaseous Diverging Spherical Detonations
}

\author{
D. Desbordes
}

Laboratoire d'Energétique et de Détonique, URA 193 du CNRS, ENSMA, Site du Futuroscope, BP. 109, 86960 Futuroscope cedex, France

\begin{abstract}
The diverging spherical detonation wave in gaseous explosives is obtained either with a point source of explosion of energy $E$ or through the transmission of a plane detonation from a cylindrical tube of diameter $d$ into a large volume. The mechanism of detonation initiation in both cases is based on the shock to detonation transition. The experimental critical conditions lead to an initiation criterion for detonation resulting from the competition between the expansion behind the leading shock wave on one hand and the shock-induced chemical heat release on the other. Whatever the type of ignition source, the detonation is obtained when the radius of curvature of the wave overcomes a particular critical value $R_{c}$ whose size includes a constant and large number of cell width $\lambda_{\mathrm{CJ}}\left(\mathrm{R}_{\mathrm{c}} \cong 20 \lambda_{\mathrm{CJ}}\right)$ and then can be considered as intrinsic to the detonative mixture used. $\lambda_{\mathrm{CJ}}$, which is the mean size of the cellular structure of a CJ detonation, is proportional to the global chemical induction length $L_{i}$, calculated in the ZND scheme, by also a large factor (generally more than 10). Two other criteria define the critical initiation energy $E_{c}$ and the critical tube diameter $d_{c}$ for obtaining detonation with respect to this intrinsic length $R_{c}$.
\end{abstract}

\section{INTRODUCTION}

The direct initiation of the diverging spherical detonation in gaseous explosives, is based on the so-called shock to detonation transition and has been generally studied via two modes of ignition. The first mode consists in the diffraction of a planar CJ or overdriven detonation wave from a tube of i.d. $d$ (or from orifices of different shapes) into a large volume [1] to [7]. The second mode is the deposition in the medium, by a sufficiently powerfull point source of explosion, of an energy $E$ creating quasiinstantaneously a strong decaying spherical shock wave [1], [8] to [11].

The critical onset of the spherical detonation has been widely studied in both cases essentially in order to define the detonability limits of a mixture. These limits must be regarded as intrinsic limits because depending on the reactive mixture for given initial conditions (of pressure $p_{0}$ and temperature $\mathrm{T}_{\mathrm{o}}$ ) and only on one well-controlled external parameter, as the critical diameter of transmission $\mathrm{d}_{\mathfrak{c}}$ of the tube, or on the critical initiation energy $E_{c}$ of the source.

In this work are summarized all the important features concerning the problem of the critical initiation of a detonation in free space in situations defined above.

\section{INITIATION BY DIFFRACTION OF A PLANAR DETONATION - MODE 1}

The first idea of Laffitte in 1925, in order to produce the spherical diverging detonation in a gaseous reactive mixture (spherical detonation had never been observed at that time), was to use a plane detonation propagating in a rigid tube, which is generally easy to initiate because of the confining, and to transmit it in a larger volume [12]. Lafitte never succeeded to obtain spherical detonation because of the too smaller size of the diameter of the tube he used with respect to the reactive mixture. Nevertheless, 
later on, after the experimental precursor work of Zeldovich et al. (1956) [1], this mode of production of spherical detonation wave was clearly demonstrated.

In this mode, the detonation regime exists in the medium contained in the tube where detonation products expand in constant cross section area. This detonation is submitted to a large perturbation when suddenly the confining disappears. Then, the detonation may :

1) go on, propagating in diverging spherical geometry or,

2) be quenched.

At the exit of the tube of diameter $d$, when the plane detonation diffracts, the two-dimensional lateral expansion propagates from the edge towards the axis of the tube and under subcritical conditions destroys completely the plane detonation wave as it penetrates into the larger volume. The plane detonation wave turns into a decaying two-dimensional curved shock wave followed by a gradually decoupling flame front.

At critical conditions, when the mean radius of curvature $R$ of the diffracted shock wave has increased to a threshold value, the onset of detonation suddenly occurs on the axis of the tube and goes throught the whole volume before to propagate close to the $\mathrm{CJ}$ conditions. A quasi spherical predetonation sphere [7] is then observed with a radius $R=R_{c}$ (as displayed in Fig. 1).
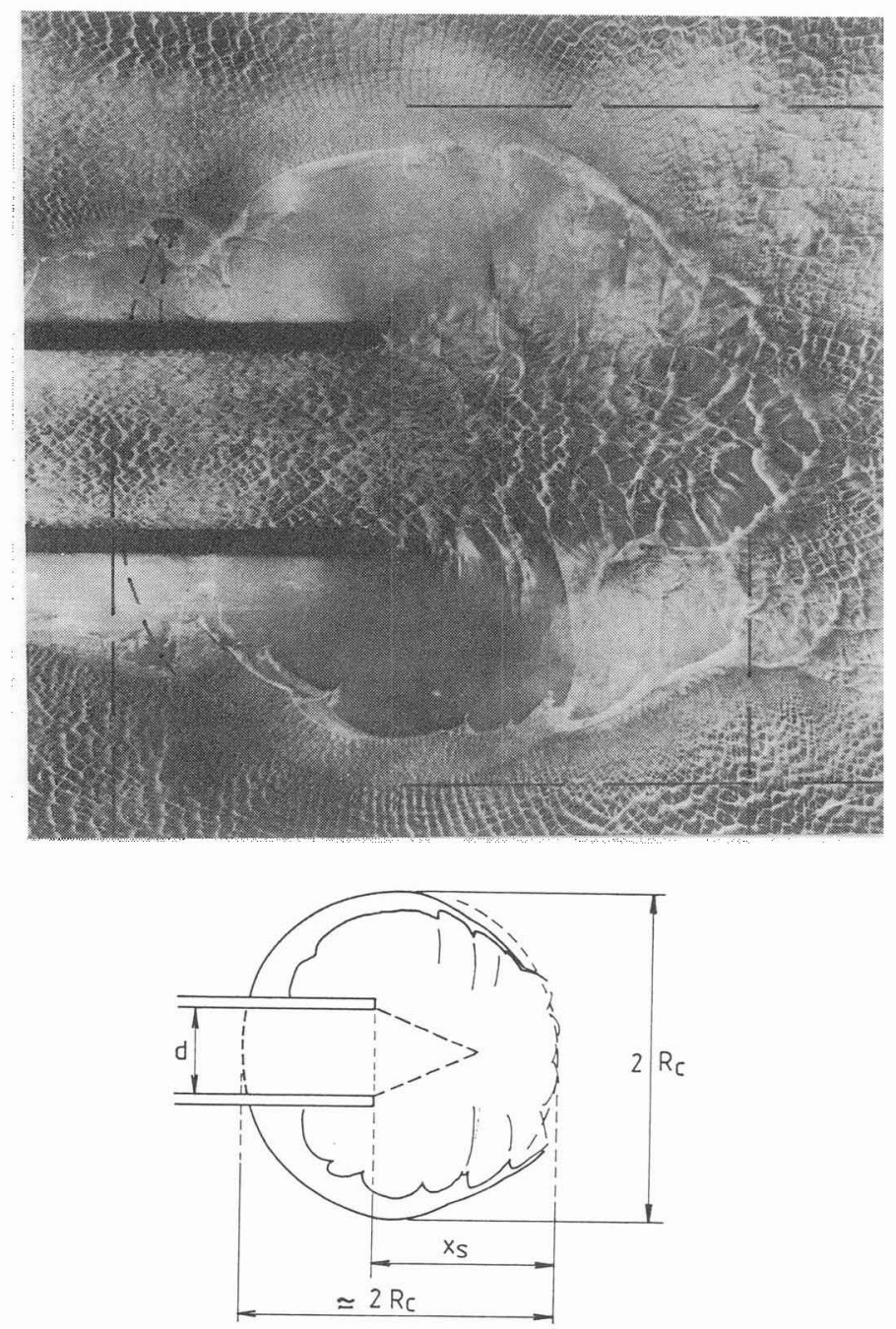

Fig. 1 Smoked-foil record of predetonation sphere of mean radius $\mathrm{R}_{\mathrm{C}}$ for critical transmission of a plane detonation into a large volume in $\mathrm{C}_{2} \mathrm{H}_{2}+2.5 \mathrm{O}_{2}$ mixture at $\mathrm{T}_{0}=293 \mathrm{~K}$. 
For most of the gaseous detonation mixtures currently used $\left(\mathrm{C}_{\mathrm{n}} \mathrm{H}_{\mathrm{m}} / \mathrm{O}_{2}\right.$ and $\mathrm{H}_{2} / \mathrm{O}_{2}$ or $/$ Air $)$ observations give :

$$
\mathrm{R}_{\mathrm{c}} \cong 1.6 \mathrm{~d}
$$

So, at that mean radius, independently of the mixture used and of the size $\mathrm{d}$ of the tube, the shock wave strength is quasi identical if referred to the initial conditions for a plane-CJ diffracted detonation wave. Moreover, many experimental data provide a noteworthy correlation between $R_{c}$ and the detonation cell size $\lambda_{\mathrm{CJ}}$ of the mixture [13], as :

$$
\mathrm{R}_{\mathrm{c}} \cong 20 \lambda_{\mathrm{CJ}}
$$

Thus, considering Eqs. (1) and (2), the classical notion of critical tube diameter $d_{c}$ of transmission of a $\mathrm{CJ}$ plane detonation wave into a large volume can be defined and appears as a direct consequence of the $\mathrm{R}_{\mathrm{c}} \equiv 20 \lambda_{\mathrm{CJ}}$ requirement, i.e. :

$$
\mathrm{d}_{\mathrm{c}} \cong \frac{20 \lambda_{\mathrm{CJ}}}{1.6} \cong 13 \lambda_{\mathrm{CJ}}
$$

If now we consider the diffraction of a plane overdriven detonation wave which turns into a $\mathrm{CJ}$ spherical detonation wave, experiment shows that at critical conditions, the $R_{c} \cong 20 \lambda_{C J}$ rule remains valid [14]. Nevertheless, size of the critical diameter $d_{c}$ decreases depending on the strength of the plane detonation wave. For not too high values of $D / D_{C J}$ and depending on the reactive mixture [14], $d_{c}$ is found a decreasing function of $D / D_{C J}$ which follows the $d_{c}=13 \lambda$ rule. Detonation cell size $\lambda$ depends on $\mathrm{D} / \mathrm{D}_{\mathrm{CJ}}$ as the following :

$$
\frac{\lambda}{\lambda_{\mathrm{CJ}}} \cong \frac{\mathrm{D}}{\mathrm{D}_{\mathrm{CJ}}} \exp \frac{\mathrm{E}_{\mathrm{A}}}{\mathrm{RT}_{\mathrm{ZND}}}\left[\left(\frac{\mathrm{D}_{\mathrm{CJ}}}{\mathrm{D}}\right)^{2}-1\right]
$$

As $\mathrm{D} / \mathrm{D}_{\mathrm{CJ}}$ increases from 1 , this kind of source tends progressively towards the ideal point source of explosion (at least in the decreasing part of the relationship).

\section{INITIATION BY AN EXPLOSION POINT SOURCE - MODE 2}

In his experiment in 1925 [12], Laffitte succeeded for the first time to obtain a spherical diverging detonation wave by the action of high explosive point source. At that time, this diverging propagation of the wave was rejected since 1917 [15] by Jouguet. Neverteheless around the 40's, independantly Taylor [16] and Zeldovich [17] gave a particular solution of the expansion of the detonation products behind such a $\mathrm{CJ}$ wave.

In a general way, the critical initiation of spherical detonation does not depend on the type of source if it can be considered as an ideal strong point source of explosion (cf. Taylor [18] and Sedov [19]) as for instance, laser spark, exploding wire or detonation of high explosive. In such conditions, the energy deposition shows the same trend and the resulting shock wave produced and its decay may be scaled by only one parameter, i.e the energy of the source $E$ (for fixed $\rho_{o}$ ). The intense decaying spherical shock wave produced in the reactive mixture turns into an overdriven expanding detonation wave. This detonation presents a very large curvature of its front and is submitted to the action of the intense rear expansion wave and then decays rapidly as $\mathrm{R}$ increases. For critical initiation, at a radius $\mathrm{R}$ $=R_{S}$, the detonation is totally quenched. The very fine cellular system observed for $R<R_{S}$, with cell size $\lambda<\lambda_{C J}$, disappears [13] (cf. Fig. 2). It can be noticed that when approaching the "CJ" regime of the wave (velocity $D \cong D_{C J}$ ) the curved detonation does not resist the rear expansion. A spherical shock followed by a decoupling flame is then observed. As the shock wave propagates up to $R=R_{\mathcal{C}}\left(>R_{\mathcal{S}}\right)$, the sudden onset of detonation occurs in the whole volume at different locations in the unburned compressed layer located between the shock front and the flame (cf. Fig. 3). As a remarkable result, this radius $R_{C}$ is correlated to the cell width $\lambda_{C J}$, as in the mode 1 of initiation, by a factor of about 20 for common reactive mixtures used, independently of the type of the energy source if it is strong enough (cf. Fig. 4). 

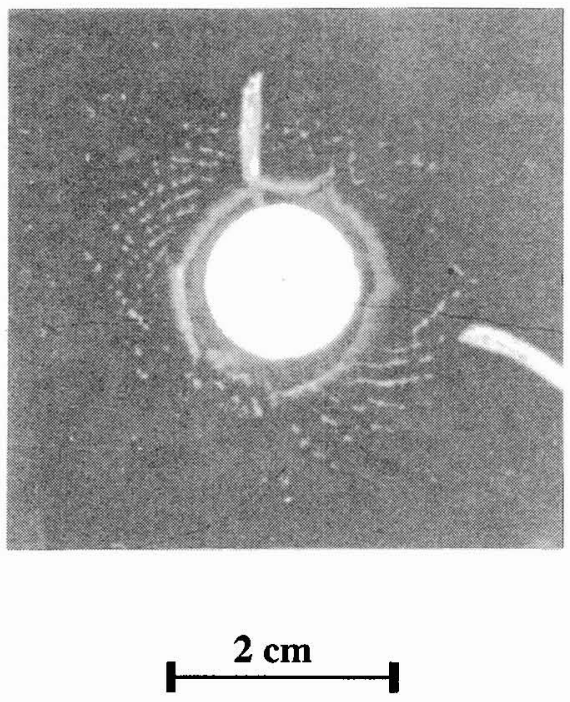

Fig. 2 Smoked-foil record of the detonation cellular structure near the initiation source and its failure in critically initiated spherical detonation in $\mathrm{C}_{2} \mathrm{H}_{2}+2.5 \mathrm{O}_{2}$ mixture at $\mathrm{T}_{0}=293 \mathrm{~K}$ and $\mathrm{p}_{\mathrm{o}}=30$ torr $\left(\lambda_{\mathrm{CJ}}=5 \mathrm{~mm}-\mathrm{R}^{*} \cong 20 \mathrm{~mm}\right)$.
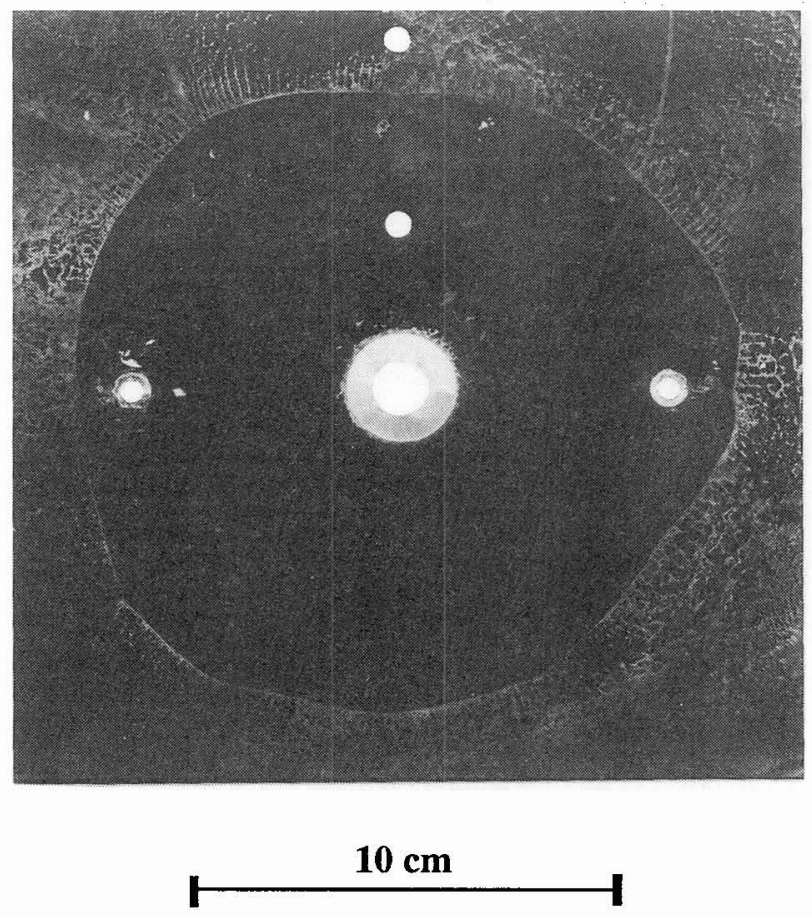

Fig. 3 Smoked-foil record of the predetonation sphere of mean radius $\mathrm{R}_{\mathrm{c}}$ for critical detonation initiation in $\mathrm{C}_{2} \mathrm{H}_{2}+2.5 \mathrm{O}_{2}$ mixture at $\mathrm{T}_{\mathrm{o}}=293 \mathrm{~K}$ and $\mathrm{p}_{\mathrm{o}}=40$ Torr $\left(\lambda_{\mathrm{CJ}}=4 \mathrm{~mm}\right)$. 


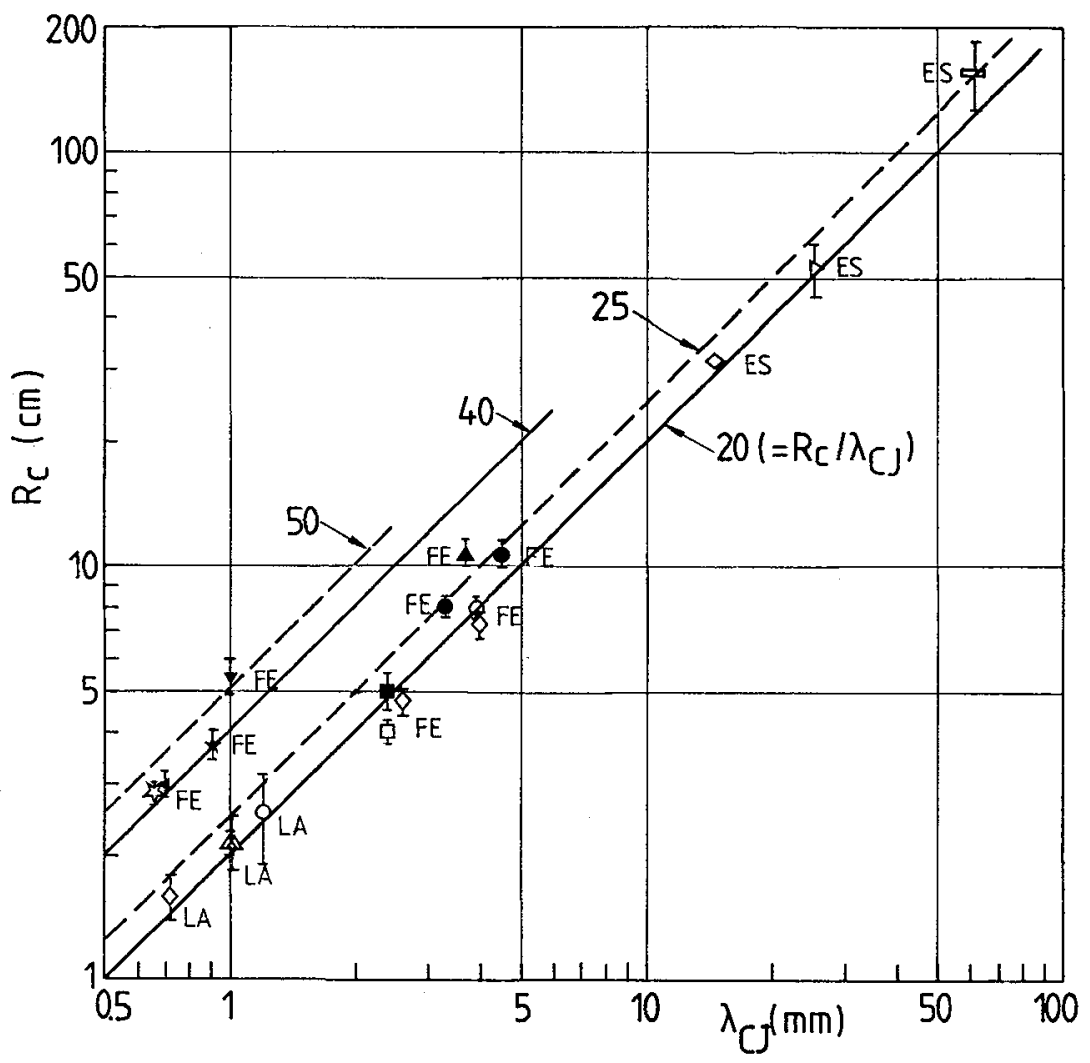

Fig. 4 Critical predetonation radius $R_{c}$ versus cell size $\lambda_{C J}$ in various reactive mixtures for different initiation sources. (FE : Exploding wire - LA : Laser spark - ES : High Explosive $)-\mathrm{C}_{2} \mathrm{H}_{2}+\mathrm{O}_{2}-\mathrm{C}_{2} \mathrm{H}_{2}+2.5 \mathrm{O}_{2}-\Delta \mathrm{C}_{2} \mathrm{H}_{2}+2.5 \mathrm{O}_{2}+3.5 \mathrm{Ar}(50 \% \mathrm{Ar})$ $\Delta \mathrm{C}_{2} \mathrm{H}_{2}+2.5 \mathrm{O}_{2}+9 \mathrm{Ar}(72 \% \mathrm{Ar}) \star \mathrm{C}_{2} \mathrm{H}_{2}+2.5 \mathrm{O}_{2}+10 \mathrm{Ar}$ (75\% Ar) $\nabla \mathrm{C}_{2} \mathrm{H}_{2}+2.5 \mathrm{O}_{2}+13 \mathrm{Ar}(79 \% \mathrm{Ar})-\mathrm{C}_{2} \mathrm{H}_{2}+2.5 \mathrm{O}_{2}+5 \mathrm{~N}_{2}-$ $\mathrm{H}_{2}+\operatorname{Air}(\phi=1)-\mathrm{C}_{2} \mathrm{H}_{4}+\mathrm{Air}(\phi=1.3)-\mathrm{C}_{3} \mathrm{H}_{8}+\mathrm{Air}(\phi=1)$

(white point $=$ spherical propagation - black point $=$ hemispherical propagation).

More recently, some experiments [20] [21] have shown that, for some reactive mixtures diluted by a large amount of a monoatomic inert as $\mathrm{He}, \mathrm{Ar}$ or $\mathrm{Kr}$, the critical radius $\mathrm{R}_{\mathrm{c}}=\mathrm{k} \lambda_{\mathrm{CJ}}$ presents a constant $\mathrm{k}$ depending on the amount of diluent and is, for a dilution of 75 to $80 \%$, about twice the common value, i.e. $\mathrm{k} \cong 40-44$. In such mixtures the $R_{c}=1.6 d_{c}$ rule holds, meaning that similarity concerning thermodynamical characteristics required for initiation is maintained.

In a general way, instabilities that generally arise during the process of chemical energy release in the detonation front depend deeply on the amplitude of the reduced global activation energy $\mathrm{E}_{\mathrm{A}} / \mathrm{RT}_{\mathrm{ZND}}$ of the chemical system and undoubtely at the origin of the cellular and subcellular structure of the detonation wave [22]. For the systems mentionned above of particularly low values of $E_{A} / R_{Z N D}(\cong 5)$ in comparaison with values of common reactive systems, the cellular structure is very regular (based on one particular frequency of instability). Moreover, detonation in such systems propagating in tubes exhibits a three-dimensional structure depending strongly on the rigid boundaries and its failure (initiation) because of lack of instrinsic instabilities of higher frequencies is more easy (difficult) to obtain [23] ([24]) when submitted to an external perturbation. In connexion with that, in diverging propagation the selfsustained detonation appears not so resistant to expansion and requires a larger critical radius of curvature $R_{c}$ (if referred to $\lambda_{C J}$ ) and then larger critical tube diameter $d_{c}$ and critical initiation energy $E_{\mathfrak{c}}[13][21]$. 


\section{DISCUSSION}

In the precursor work of Zeldovich et al. (1956), who studied carefully these two modes of initiation of detonation, is established what we called the "Zeldovich criterion" for initiation. It may be summarized into necessary conditions concerning two parameters (intensive and extensive) of the initiation problem, respectively :

$1^{\circ}$ ) the strength $\mathrm{p}_{\mathrm{s}}$ of the shock wave must be larger than a threshold value (to insure at least the self ignition of the reactive mixture), i.e. $p_{s} \sim p_{Z N D}>p_{0}$ and,

$2^{\circ}$ ) the radius of curvature $R$ of the wave is at least equal to the chemical induction length $L_{i}{ }^{(1)}$ of the mixture, $\mathrm{L}_{\mathrm{i}}$ remaining the sole characteristic length of the problem.

So the critical initiation energy may be written as :

$$
\mathrm{E}_{\mathrm{c}} \sim \mathrm{PZND} \mathrm{L}_{\mathrm{i}}{ }^{3}
$$

Experiments on critical initiations performed after that work confirm qualitatively such a criterion [25], but give no quantitative estimation of energy $E_{c}$.

In fact, experiments [7]-[11] reported above show clearly that onset of spherical detonation occurs at criticallity for a very large radius of curvature of the wave (at least one order of magnitude higher than the cell size $\lambda_{C J}$ ).

The physical mechanism for the onset of detonation considering a progressive distance from the source is the following in the two modes [13]:

$1^{\circ}$ ) at the beginning of the process the detonation regime exists (CJ or overdriven plane detonation in mode 1 and overdriven spherical detonation in mode 2 ).

$\left.2^{\circ}\right)$ this detonation is destroyed by the strong negative gradient of the expansion wave behind the curved detonation front by respectively :

- the lateral expansion starting from the corner and converging to the axis of the tube in the case of the sudden disappearing of confining,

- the central spherical expansion in the case of initiation by the point source.

$3^{\circ}$ ) as the wave recovers a small curvature with regard to the cell size $\lambda \mathrm{CJ}$, the onset of the selfsustained detonation occurs.

For simplicity of analysis, we have considered only the second initiation mode because of point symmetry (notice that for mode 1, diffraction of a highly overdriven plane detonation wave by a very small tube diameter is quite representative of the case considered because in such situation the shape of the source may be ignored). In that case, the curved multiheaded detonation exists for very small $R$, because of the large strength of the wave (D/D $\mathrm{D}_{\mathrm{CJ}}>1$ and $\left.\mathrm{p}_{\mathrm{S}} \gg \mathrm{pZND}\right)$. Inside the sphere of radius $\mathrm{R}^{*}$, where $R^{*}$ is the radius of the spherical shock wave where the energy of the source $E$ is balanced by the chemical energy release, i.e. :

$$
\mathrm{R}^{*}=\left(\frac{\mathrm{E}}{\frac{4}{3} \pi \rho_{\mathrm{o}} \mathrm{Q}}\right)^{1 / 3}
$$

the motion of the wave is governed by the energy deposition and the combustion observed is the "induced" detonation regime. At $\mathrm{R}=\mathrm{R}^{*}$, the detonation regime still exists, because cellular structures are almost recorded. So, the chemical heat release has played a role at that radius equivalent for the propagation of the shock, from the point of view of energy, to the external source. For $R\left(=R_{S}\right)$ slightly larger than $R^{*}$, the three-dimensional structure of the detonation vanishes. Most of the experiments show [13] clearly that in first approximation :

(1) The chemical induction length used by Zeldovich and coworkers was certainly a kind of hydrodynamic mean scale separating the shock front and the flame in the detonation structure considered in the ZND frame. A proof of that is reported in the same work where critical tube diameter is correlated to $\mathrm{L}_{i}$ by the relationship $d_{c}=15 \mathrm{~L}_{i}$ which is very close to the $\mathrm{d}_{\mathrm{c}}=13 \lambda_{\mathrm{CJ}}$ rule. So, $\mathrm{L}_{\mathrm{i}}$ in that work was representative approximately of the size of the cell spacing of the reactive mixture even if at that time the intrinsic detonation cellular structure had not been yet discovered. 
$\left.1^{\circ}\right) \mathrm{R}_{\mathrm{S}} \cong \mathrm{R}^{*}$ and

$2^{\circ}$ ) $R_{s}$ is equal to $0.2 R_{c}$, so

$$
R_{s} \cong R^{*} \cong 0.2 R_{c}\left(\cong 4 \lambda_{C J}\right)
$$

Considering Eqs (2) (6) (7) and the approximate relationship $D_{C J}{ }^{2}=2\left(\gamma^{2}-1\right) Q$, the critical energy of initiation can be expressed by :

$$
E_{c}=B \rho_{o} D_{C J}^{2} R_{c}^{3}
$$

where

$$
B=\frac{4 \pi}{750\left(\gamma^{2}-1\right)}
$$

This expression gives generally a reasonably good estimation of the energy of real sources [13][21] and is very close to those given by Vasiliev and Grigoriev [26], Lee [27] and Knystautas et al [28].

In other respects, the small curvature of the wave front for the existence of the selfsustained detonation is highlighted in the experimental study of Murray et al [29]. Detonations propagate in tube with removing wall (plastic film) of different thicknesses which permit to vary the rear expansion rate. The authors demonstrated clearly that a too strong rear expansion destroys the detonation wave and a criterion for the critical existence of the self-sustained propagation of the "curved" detonation in different chemical systems has been given concerning the radius of the wave front, i.e. $R_{c}>16 \lambda_{C J}$.

Recently, in correlation with this problem of existence of curved self-sustained detonation wave, $\mathrm{He}$ and Clavin [30] bring an interesting contribution to the problem of initiation of diverging detonations. They demonstrate from simulation that existence of curved generalized CJ detonation wave needs a minimum radius of curvature $R_{c}$ of the wave of amplitude, at least two or three order of magnitude larger than $L_{i}$, the only scale of the problem, in agreement with observations [11] given above.

\section{CONCLUSIONS}

Critical direct initiation of spherical gaseous detonations in different gaseous reactive systems has been investigated.

Two modes of initiation are studied :

$1^{\circ}$ ) transmission into a large volume of a plane CJ or overdriven detonation wave propagating in a di.d. tube and

$2^{\circ}$ ) deposition of an energy $E$ by an ideal strong point source of explosion.

As generally observed:

$1^{\circ}$ ) The onset of spherical detonation occurs after a predetonation sphere of radius $R=R_{c}$ which appears to be an intrinsic parameter of the explosive mixture linked to the cell spacing $\lambda_{\mathrm{Cr}}$ by a large and constant factor (generally 20).

$2^{\circ}$ ) as a consequence of 1 ):

a) the detonation wave which exists generally near the "source" cannot resist strong curvature effects, even in CJ conditions. So, the self-sustained CJ detonation wave needs a maximum curvature in comparison to $\lambda_{C J}$. When radius of detonation takes the value $R_{c}$ roughly, the detonation may ignore the rear expansion wave. This can be summarized by a competition between the rear expansion effects and the chemical production in the $R_{c}=20 \lambda_{C J}$ relationship. b) $R_{c}$ may vary from few millimeters for common $\mathrm{C}_{n} \mathrm{H}_{\mathrm{m}}-\mathrm{H}_{2} / \mathrm{O}_{2}$ reactive mixtures at ambiant conditions to few meters for less detonable mixtures as $\mathrm{C}_{\mathrm{n}} \mathrm{H}_{\mathrm{m}}-\mathrm{H}_{2}$ /Air mixtures.

c) the critical diameter of transmission $d_{c}$ is linked to $\lambda$ by the classical relationship $d_{c}=13 \lambda$, $\lambda=\lambda_{\mathrm{CJ}}$ for the $\mathrm{CJ}$ wave and results from the $\mathrm{R}_{\mathrm{C}}=20 \lambda_{\mathrm{CJ}}$ requirement.

d) the critical initiation energy $E_{c}$ of the strong point source of explosion varies as : 


$$
E_{c} \sim R_{c}^{3}
$$

and may be very large, owing to the fact that $R_{c}$ contains a large number of cells $\lambda_{C J}(20)$, each cell includes itself generally a large number of chemical induction length $L_{i}$ (generally 30 for $\mathrm{C}_{n} \mathrm{H}_{\mathrm{m}}$ /Air systems), i.e. $\mathrm{R}_{\mathrm{c}} \cong 600 \mathrm{~L}_{\mathrm{iCJ}}$.

Discrepancy from classical rules is observed in detonation presenting a very regular cellular systems. In these systems, the critical radius of curvature $R_{c}$ of a detonation is larger if compared to $\lambda_{\mathrm{CJ}}$ (or $\mathrm{LiCJ}_{\mathrm{CJ}}$ ) than in common reactive mixtures and propagation in rigid tubes more dependent on confinement. This emphasizes the fact that the three-dimensional structure of detonation plays a specific role in the propagation, the initiation and failure of the self-sustained detonation wave, which cannot be explained on the simple basis of the ZND structure of the wave.

\section{References}

[1] Zeldovich Ya. B., Kogarko S.M. and Simonov N.N., J. Phys. Technol. 26 (1956), 17441772.

[2] Mitrofanov V.V. and Soloukhin R.I., Dokl. Akad. Nauk. SSSR. 159 (1964), 1003-1006.

[3] Matsui H. and Lee J.H., Seventeenth International Symposium on Combustion (1978), 12691280 .

[4] Edwards D.H., Thomas G.O., Nettleton M.A., AIAA Progr. Astron. Aeronautics 75 (1981), 341-357.

[5] Moen I.O. et al., Nineteenth International Symposium on Combustion (1982), 635-644.

[6] Desbordes D. and Vachon M., AIAA Progr. Astron. Aeronautics 106 (1986), 131-143.

[7] Lee J.H., Knystautas, R. and Bach G.G. Theory of explosions, MERL Report 69-10, Mc Gill University, Montreal, Canada.

[8] Klimkin, V.F., Soloukhin, R.I. and Wolanski, P., Comb. and Flame 21-1 (1973), 111-117.

[9] Kamel, M.M. and Oppenheim, A.K., Aerotec. Missili Spazio, 2, 122-134.

[10] Edwards, D.H., Hooper, G., Morgan, J.M. and Thomas, G.O., J. Phys.D. Al. Phys., 11 (1978), 2103-2117.

[11] Desbordes, D., AIAA Progr. Astron. Aeronautics 106 (1986), 166-180.

[12] Lafitte, P., Ann. Phys., 10(4) (1925), 623-634.

[13] Desbordes, D., Aspects stationnaires et transitoires de la détonation dans les gaz : Relation avec la structure cellulaire du front, Thesis $n^{\circ} 498$ of the University of Poitiers, France (1990).

[14] Desbordes, D., Brissot, D. et Guerraud, C., Ann. Phys. Fr., 14 (1989), 629-635.

[15] Jouguet, E., La Mécanique des Explosifs (1917) DOIN, Paris.

[16] Taylor, G.I., Proc. R. Soc., A200 (1950), 235-247.

[17] Zeldovich Ya.B., Zh.E.T.P., 12 (1942), 389-406.

[18] Taylor, G.I., Proc. R. Soc., A201 (1950), 159-174.

[19] Sedov, L.I., Similarity and Dimensional methods in mechanics (1959) Academic Press, Inc. NY.

[20] Moen, I.O., Sulmistras, A., Thomas, G.O., Bjerketvedt, D. and Thibault, P.A., AIAA Progr. Astron. Aeronautics, 106 (1986), 220-243.

[21] Desbordes, D., Guerraud, C., Hamada, L. and Presles, H.N., AIAA Prog. Astron. Aeronautics, 153 (1993), 347-359.

[22] Fickett, W.and Davis W.C., Detonation (University of California Press, Berkeley), (1979).

[23] Dupré, G., Peraldi, O., Lee, J.H. and Knystautas R. AIAA Prog. Astron. Aeronautics, 114 (1988), 248-263.

[24] Chue, R.S., Lee, J.H., Scarinci ,T., Papyrin, A. and Knystautas R. AIAA Prog. Astron. Aeronautics, 153 (1993), 270-282.

[25] Bull, D.C., Elsworth, J.E. and Hooper, G., Acta Astron., 5 (1978), 997-1008.

[26] Vasiliev, A.A. and Grigoriev, V.V., F.G.I.V., 16 (1980), 117-125.

[27] Lee, J.H., Ann. Rev. Fl. Mech, 16 (1984), 311-336.

[28] Knystautas, R., Guirao, C., Lee, J.H. and Sulmistras, A., AIAA Progr. Astron. Aeronautics, 94 (1984), 23-37.

[29] Murray, S.B. and Lee, J.H., AIAA Progr. Astron. Aeronautics, 106 (1986), 329-355.

[30] He, L. and Clavin, P., J. Fluid Mech., 277 (1994), 227-248. 